\title{
Recent Increased Covariability of Tropical Cyclogenesis Latitude and Longitude over the Western North Pacific during the Extended Boreal Summer
}

\author{
HAIKUN ZHAO \\ Key Laboratory of Meteorological Disaster, Ministry of Education/Joint International Research Laboratory of Climate and Environment \\ Change/Collaborative Innovation Center on Forecast and Evaluation of Meteorological Disaster/Pacific Typhoon Research Center/Earth \\ System Modeling Center, Nanjing University of Information Science and Technology, Nanjing, China
}

JIE ZHANG

Key Laboratory of Meteorological Disaster of Ministry of Education, Nanjing University of Information Science and Technology, Nanjing, China

PHILIP J. KLOTZBACH

Department of Atmospheric Science, Colorado State University, Fort Collins, Colorado

SHAOHUA CHEN

Key Laboratory of Meteorological Disaster of Ministry of Education, Nanjing University of Information Science and Technology, Nanjing, China

(Manuscript received 3 January 2019, in final form 1 August 2019)

\begin{abstract}
This study examines interdecadal changes in the interannual relationship between the extended boreal summer (May-November) tropical cyclogenesis (TCG) latitude and longitude over the western North Pacific Ocean (WNP) during 1979-2016. Increasing covariability of WNP TCG latitude and longitude is observed since 1998, which is found to be closely linked to shifting ENSO conditions and a tropical Pacific climate regime shift. Accompanied by an increasing occurrence in central Pacific (CP) ENSO events during recent decades, there has been a more consistent northwestward or southeastward shift of WNP TCG location since 1998. These coherent latitude and longitude shifts were generally not evident during 1979-97, a period characterized by a more conventional eastern Pacific (EP) ENSO pattern. Our statistical results show a robust relationship between TCG latitude and the Hadley circulation and between longitude and the Walker circulation during the period prior to and since the regime shift, and a possible physical explanation for the recent increased covariability of TCG latitude and longitude is given. During 1998-2016, there is a significant association of CP ENSO events with the intensity of both the Hadley and Walker circulations that likely caused the recent increase in the covariability of TCG latitude and longitude. However, the strong association of EP ENSO events with the intensity of the Hadley circulation but not with the Walker circulation during 1979-97 weakened the covariability of TCG latitude and longitude. In addition, changes in tropical Indian Ocean sea surface temperatures appear to also importantly contribute to the recent increased covariability of WNP TCG location.
\end{abstract}

\section{Introduction}

Tropical cyclones (TCs) are one of the most devastating and deadly natural disasters on Earth, often causing huge economic damage and great loss of life (Mendelsohn et al. 2012; Peduzzi et al. 2012). Studies

Corresponding author: Dr. Haikun Zhao, zhk2004y@gmail.com have suggested that TCs over the western North Pacific Ocean (WNP) pose an increasing threat to economic development as well as the growing population in China's coastal areas and adjacent regions (Zhang et al. 2009; Lin et al. 2014). Previous studies have mainly focused on the changes of TC frequency, TC track, and TC intensity in response to climate change (Knutson et al. 2010; Walsh et al. 2015). Forecasts of tropical 
cyclogenesis (TCG) remain challenging, however, especially beyond $\sim 12-14$ days where dynamical models show little skill (Yamaguchi et al. 2015). Therefore, enhanced understanding of changes in TC formation location could potentially aid in future TC forecasts.

The tropical Pacific climate regime shift and associated ENSO characteristic changes that occurred in the late 1990s have been well documented in previous studies (Kug et al. 2009; Lee and McPhaden 2010; McPhaden et al. 2011; Yu et al. 2011; Hu et al. 2013, 2017; Hu et al. 2018; Zhao and Wang 2019). Accompanying the climate regime shift were decadal changes in the characteristics of WNP TC activity. For example, there was a significant reduction in TC frequency (Liu and Chan 2013) and a significant increase in both the proportion of intense TCs (Wu et al. 2018) and rapidly intensifying TCs (Zhao et al. 2018). In addition, there was an apparent westward and northward shift in TC formation location (Liu and Chan 2013; Wu et al. 2015; $\mathrm{Hu}$ et al. 2018). More TCs have also tended to take westward and northward tracks since the late 1990s (Chan 2008; Liu and Chan 2013; Zhao and Wang 2016; Wu et al. 2018). These changes in WNP TC activity were thought to be closely associated with changes in the large-scale environment (Chan 2008; Liu and Chan 2013; Wu et al. 2015; Zhao and Wang 2016, 2019; Hu et al. 2018; Wang et al. 2019) as well as changes in teleconnections with tropical sea surface temperature anomaly (SSTA) patterns in response to the aforementioned climate regime shift (Kim et al. 2010; Huo et al. 2015; Yu et al. 2015; Gao et al. 2018; Hu et al. 2018; Zhao et al. 2018; Zhao and Wang 2019). However, the change in the interannual relationship between TCG latitude and TCG longitude over the WNP basin in response to the climate regime shift has been less studied.

Studies have suggested that ENSO has a significant impact on the interannual variability of WNP TCG location, with many studies noting that there is a southeastward shift during El Niño years and a northwestward displacement during La Niña years (Lander 1994; Wang and Chan 2002; Camargo and Sobel 2005). We confirm this previously documented relationship here by showing that there is a significant correlation between WNP TCG location and the Niño-3.4 index during the full period of this study from 1979 to 2016. Both TCG latitude and TCG longitude during the boreal extended summer from May to November strongly correlate with the Niño-3.4 index, with respective correlation coefficients of -0.78 and 0.66 that are significant at a $95 \%$ confidence level (Table 1). We also find stronger covariability of TCG latitude and longitude over the WNP basin during 1979-2016, with a correlation coefficient of -0.54 that is significant at a $95 \%$ confidence level (Table 1). Associated with a well-
TABLE 1. Correlation between TCG latitude and TCG longitude from JTWC and the Niño-3.4 index during 1979-2016 and the two subperiods 1998-2016 and 1979-97. The correlations of TC latitude and TCG longitude during these three periods are also shown. An asterisk indicates that the correlation is significant at a $95 \%$ confidence level.

\begin{tabular}{lccc}
\hline \hline \multicolumn{1}{c}{ Correlations } & $1979-2016$ & $1979-97$ & $1998-2016$ \\
\hline Niño-3.4 and TCG lat & $-0.78^{*}$ & $-0.74^{*}$ & $-0.83^{*}$ \\
Niño-3.4 and TCG lon & $0.66^{*}$ & $0.60^{*}$ & $0.74^{*}$ \\
TCG lat and TCG lon & $-0.54^{*}$ & -0.38 & $-0.58^{*}$ \\
\hline
\end{tabular}

documented shifting ENSO and Pacific climate shift during the recent decades [e.g., more La Niña and central Pacific (CP) El Niño events and a predominantly cool Pacific decadal oscillation (PDO) phase], studies have suggested that there is an apparent northwestward shift of WNP TCG location (Liu and Chan 2013; Wu et al. 2015; Hu et al. 2018; Zhao and Wang 2016, 2019). These studies have only given a qualitative analysis of the changes in TC frequency over the different subregions of the WNP basin but have not documented a corresponding change in the interannual relationship between TCG latitude and TCG longitude over the WNP basin associated with the climate regime shift.

Our objective in this study is to evaluate changes in the interannual covariability of WNP TCG latitude and longitude with specific emphasis on the importance of the increasing occurrence of CP ENSO events since the late 1990s. The reminder of this study is arranged as follows. Section 2 describes the data and methods, as well as definitions of various ENSO indices and calculations of the intensity of the Walker and Hadley circulations. Changes in the interannual covariability of TCG latitude and longitude over the WNP basin are compared between before 1998 and after 1998 in section 3. Key factors affecting the associated interdecadal changes of the interannual covariability of TCG location are investigated in section 4 . Section 5 gives a summary and a discussion.

\section{Data and methods}

\section{a. TC, atmospheric, and oceanic data}

TC data are obtained from the Joint Typhoon Warning Center (JTWC) best-track dataset, including 6-h-interval latitude and longitude and maximum sustained wind speed (Chu et al. 2002). In this study, we evaluate TC activity during the extended boreal summer from May to November during 1979-2016 and over the WNP basin $\left(0^{\circ}-30^{\circ} \mathrm{N}, 120^{\circ} \mathrm{E}-180^{\circ}\right)$, excluding the South China Sea. We also define a subregion of the WNP at $5^{\circ}-22.5^{\circ} \mathrm{N}, 127.5^{\circ}-160^{\circ} \mathrm{E}$, which is termed the main development region (MDR) in this study. During the 
extended boreal summer, about $80 \%$ of all WNP TCs formed in the MDR. The Dvorak technique of estimating TC intensity from satellite became routine in the mid- to late 1970s. About 19 TCs occur during the extended summer, accounting for $\sim 90 \%$ of the annual total number of TCs (i.e., 21 TCs) over the WNP basin. Only TCs with an intensity greater than or equal to tropical storm intensity are considered in this study. The changes in the interannual covariability of TCG latitude and longitude observed with the JTWC best tracks between before 1998 and after 1998 are also confirmed by using best tracks from the Shanghai Typhoon Institute of the China Meteorological Administration (CMA STI; Ying et al. 2014) and the Japan Meteorological Agency (JMA; Kunitsugu 2012). Such a consistent trend using each of the three best-track datasets implies that changes in the covariability of TCG latitude and longitude over the WNP basin are real and not a data artifact. This will be discussed in more detail in section 3 .

Monthly atmospheric variables are obtained from the National Centers for Environmental Prediction-U.S. Department of Energy reanalysis (R2; Kanamitsu et al. 2002). Monthly sea surface temperatures (SSTs) are taken from the National Oceanic and Atmospheric Administration (NOAA) Extended Reconstructed SST, version 4 (ERSSTv4; Huang et al. 2015).

\section{b. ENSO}

Various ENSO indices are used in this study to investigate the interannual relationship of the ENSO state change with TCG location between before 1998 and after 1998. The Niño-3.4 index, defined as SSTAs over $5^{\circ} \mathrm{S}-$ $5^{\circ} \mathrm{N}, 170^{\circ}-120^{\circ} \mathrm{W}$, is frequently used to describe ENSO state changes. Studies have suggested an increasing occurrence of CP ENSO events since the late 1990s (Ashok et al. 2007; Yu and Kao 2007; Kao and Yu 2009; Kug et al. 2009; Lee and McPhaden 2010). Eastern Pacific (EP) and CP ENSO events can exert distinctly different teleconnected impacts on climate and extreme weather events around the globe (Yu et al. 2012; Xiang et al. 2013; Cai et al. 2015; Zhao and Wang 2016, 2019; Hu et al. 2018). There is considerable interest in exploring the impact of a shifting ENSO on changes in the interannual covariability of TCG latitude and longitude over the WNP basin. However, CP and EP ENSO events cannot be distinguished well using the Niño-3.4 index. To better separate CP and EP ENSO events, the CP ENSO index and EP ENSO index are calculated following the method proposed by Kao and Yu (2009) and Yu and Kim (2010) using a regression-EOF analysis to identify the strengths of the CP and EP types of ENSO. The El Niño Modoki index (EMI) proposed by Ashok et al. (2007) and examined in many other studies (Kim et al. 2009; Chen and
Tam 2010; Hong et al. 2011; Zhao and Wang 2016) is also used to represent CP ENSO events to further confirm the robustness of the impact of CP ENSO events.

\section{c. Intensity of Walker and Hadley circulations}

Previously, a close association of TCG location over the WNP basin with the Walker and Hadley circulations has been documented (Chu 2002; Wang and Enfield 2003; Zhou and Cui 2008; Wang et al. 2013; Sharmila and Walsh 2018; Studholme and Gulev 2018). Changes in the interannual relationship between the intensity of the Walker and Hadley circulations and TCG locations are further examined between pre-1998 and post-1998. The strength of the Hadley circulation during these two periods is quantified following Oort and Yienger (1996) and $\mathrm{Yu}$ et al. (2012). The vertical wind shear of the meridional wind between 200 and $850 \mathrm{hPa}(200 \mathrm{hPa}$ minus $850 \mathrm{hPa}$ ) over the tropical western North Pacific $\left(115^{\circ}-155^{\circ} \mathrm{E}\right)$ along $10^{\circ} \mathrm{N}$ is used to represent the Hadley circulation strength. Following Wang et al. (2013), the intensity of the Walker circulation is calculated as the 850-hPa zonal wind averaged over the equatorial Pacific $\left(10^{\circ} \mathrm{S}-10^{\circ} \mathrm{N}, 140^{\circ} \mathrm{E}-120^{\circ} \mathrm{W}\right)$. Note that the Walker circulation is strong when the index is negative and has a larger absolute value, whereas the Hadley circulation intensity depends on the value of vertical wind shear. Our computations suggest that both the intensity of the Walker circulation and of the Hadley circulation during 1979-2016 show an upward trend. Correspondingly, an intensified Hadley and Walker circulation can be readily seen during the recent period since $1998(-3.2$ and $-6.0 \mathrm{~m} \mathrm{~s}^{-1}$, respectively) relative to the period 1979-97 (-3.6 and $-5.3 \mathrm{~m} \mathrm{~s}^{-1}$, respectively), although the differences between these two periods are not significant at a $95 \%$ confidence level. These results agree with previous studies based on both observational and theoretical analyses (Vecchi et al. 2006; Hoyos and Webster 2012; Wang et al. 2013; McGregor et al. 2014; Sharmila and Walsh 2018).

\section{d. Tests of statistical significance}

A two-tailed Student's $t$ test is used to examine statistical significance for the correlation and composite analysis; $P$ values equal to or less than 0.05 are statistically significant in this study.

\section{Recent increase in covariability of TCG location}

\section{a. West-northwestward displacement of TCG location}

There is considerable interannual variability in TCG location from 1979 to 2016 (Fig. 1). The standard deviations of the annual average TCG latitude and 


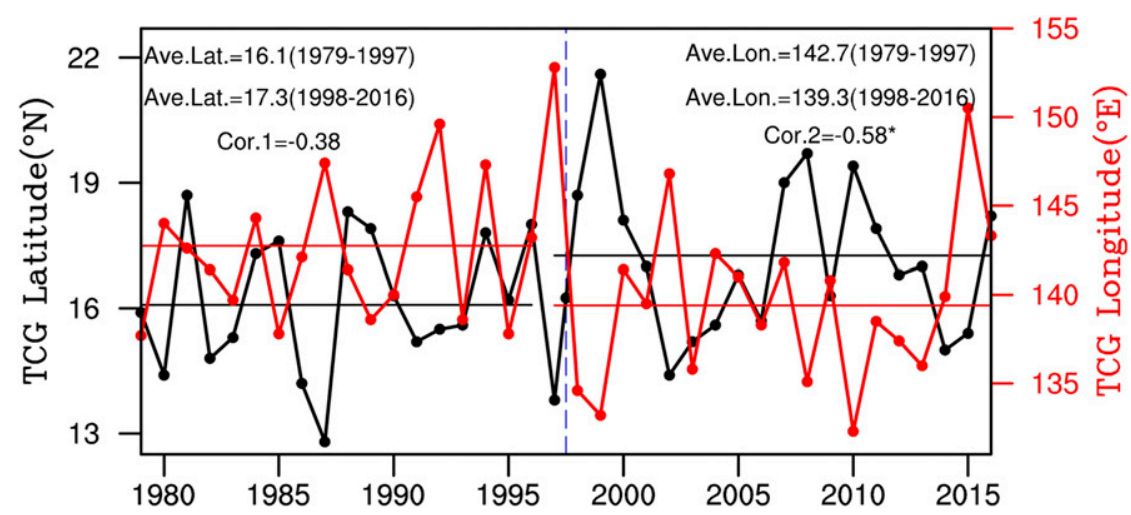

FIG. 1. Time series of TCG latitude (black) and TCG longitude (red) from JTWC over the WNP basin during 1979-2016. Correlations between the two time series and the annual average of TCG latitude and TCG longitude during 1979-97 and 1998-2016 are also respectively plotted. An asterisk indicates that the correlation is significant at a $95 \%$ confidence level.

longitude are $1.9^{\circ}$ and $4.7^{\circ}$ respectively. The interannual variation of TCG location is found to be closely associated with ENSO (Table 1). As shown in Table 1, both the TCG latitude and longitude significantly correlate with the Niño-3.4 index, with correlation coefficients of -0.78 and 0.66 during $1979-2016,-0.74$ and 0.60 during 1979-97, and -0.83 and 0.74 during 1998-2016, respectively. In addition to significant interannual variability in TCG location, a decadal change in TCG location has occurred, with a westward and northward shift in TCG location over the WNP basin during the recent period. The annual average TCG latitude and longitude are $17.3^{\circ} \mathrm{N}$ and $139.3^{\circ} \mathrm{E}$ during $1998-2016$ and $16.1^{\circ} \mathrm{N}$ and $142.7^{\circ} \mathrm{E}$ during $1979-97$. The differences in annual average TCG latitude $\left(1.2^{\circ}\right)$ and longitude $\left(-3.4^{\circ}\right)$ between these two periods are significant. This northwestward displacement of WNP TCG location has been observed in many previous studies (Liu and Chan 2013; Wu et al. 2015; Zhao and Wang 2016; Hu et al. 2018). These studies attributed changes in the largescale environment associated with the recent climate regime shift to the northwestward shift in TCG location over the WNP basin during the recent decades. These changes include vertical wind shear, vertical motion, midlevel relative humidity, and low-level relative vorticity associated with changes in large-scale atmospheric phenomena such as a weaker monsoon trough over the WNP basin and a westward shift of the WNP subtropical high and associated tropical upper tropospheric trough in response to the climate regime shift that occurred in the late 1990s (Fig. 2). Several possible physical mechanisms for the northwestward shift in TCG location over the WNP basin have been given in previous studies based on qualitative analyses (Wu et al. 2015; Hu et al. 2018; Zhao et al. 2018).
Our results have been obtained from the JTWC besttrack dataset. The results from the JTWC best track are not consistent with results in the shift of TCG location over the WNP basin when using the best-track datasets from the JMA and CMA_STI. A significant westward shift of TCG location over the WNP basin can also be found from these two best-track datasets, but while

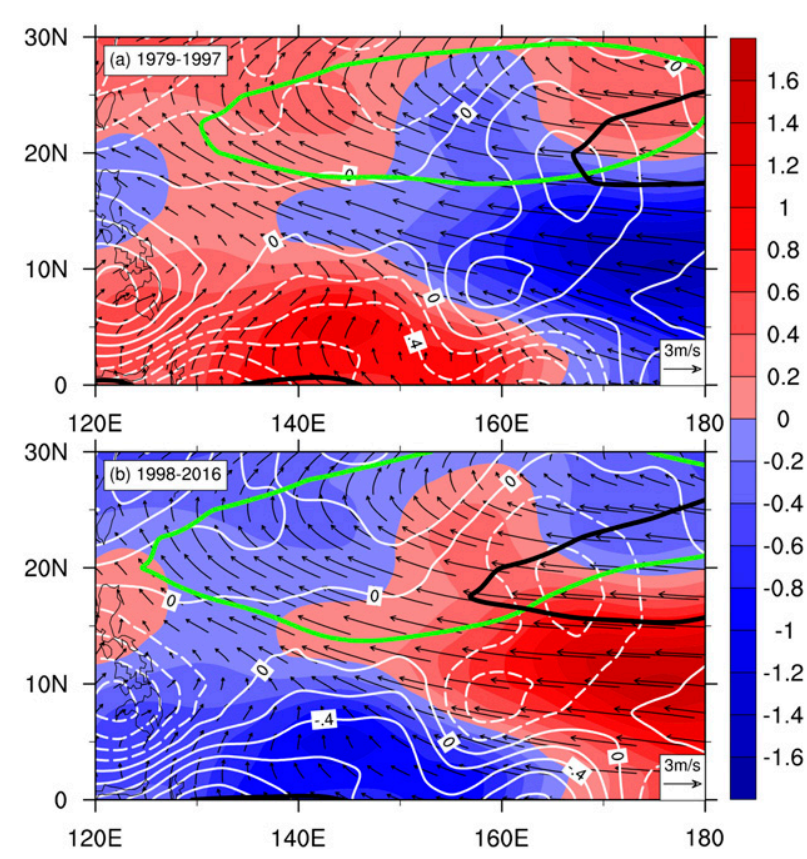

FIG. 2. Anomaly of vertical (200 minus $850 \mathrm{hPa}$ ) wind shear (shading; $\mathrm{m} \mathrm{s}^{-1}$ ), 500-hPa vertical velocity (contours; $\mathrm{Pa} \mathrm{s}^{-1}$ ), and 850-hPa wind (vectors) during (a) 1979-97 and (b) 1998-2016. Green and black lines are respectively the WNP subtropical high defined with $5875 \mathrm{gpm}$ for 500-hPa geopotential height and the tropical upper tropospheric trough defined with $3 \times 10^{-6} \mathrm{~s}^{-1}$ for 200-hPa relative vorticity. 

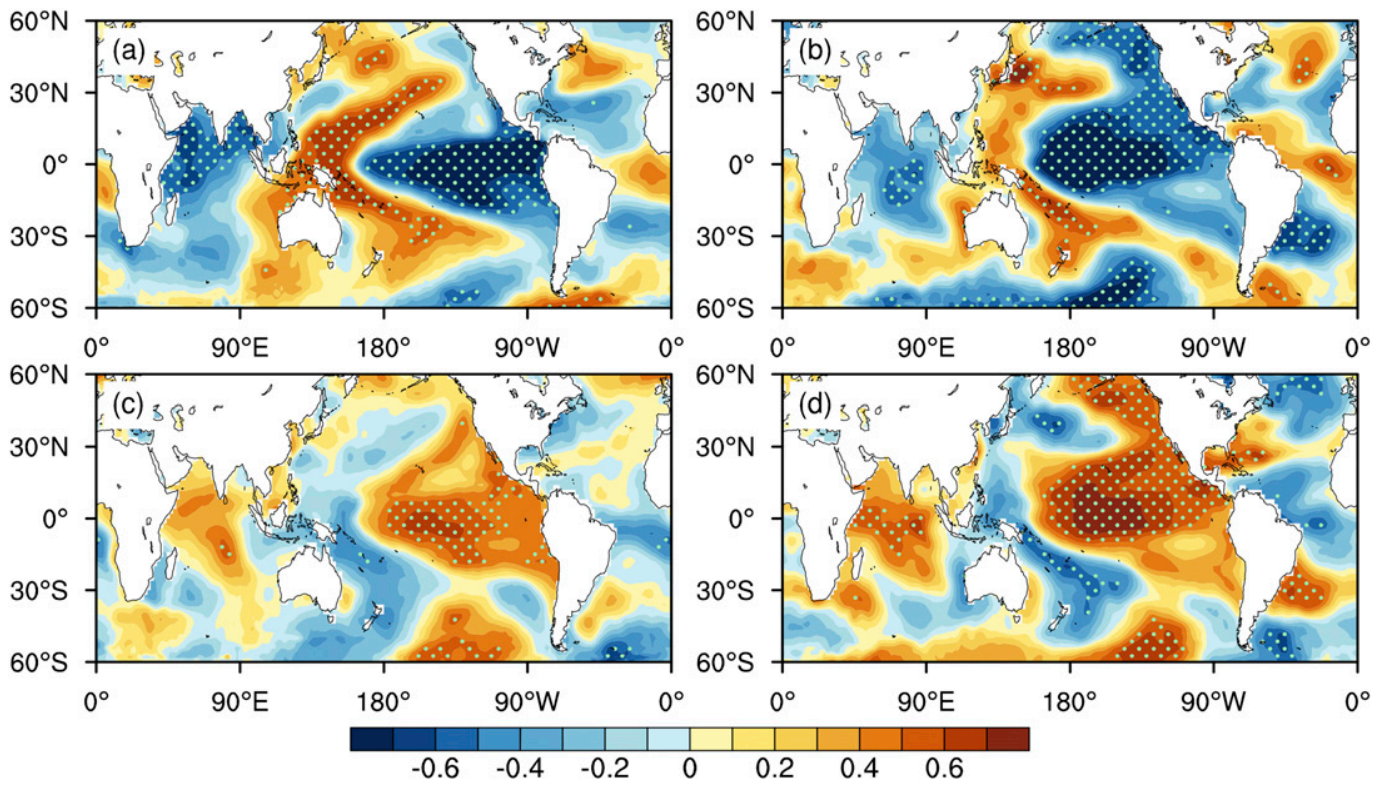

FIG. 3. Correlation maps of TCG (a),(b) latitude and (c),(d) longitude from JTWC with SST during (left) 1979-97 and (right) 1998-2016. White dots indicate that the values are significant at a 95\% confidence level.

there is a northward displacement of TCG location over the WNP basin using either the JMA or the CMA_STI best-track dataset, these differences are not significant. The annual average TCG latitude is $16.0^{\circ} / 17.3^{\circ} \mathrm{N}$ and the longitude is $141.3^{\circ} / 140.3^{\circ} \mathrm{E}$ during $1998-2016$, and they are $15.8^{\circ} / 16.6^{\circ} \mathrm{N}$ and $142.5^{\circ} / 142.7^{\circ} \mathrm{E}$ during $1979-97$. The values before and after the forward slashes are from the CMA_STI and JMA, respectively. Differences in annual average TCG latitude and longitude between these two periods are $0.2^{\circ} / 0.7^{\circ}$ and $-1.2^{\circ} \%-2.4^{\circ}$, respectively, from CMA STI and JMA. Detailed analyses of the quality of the TC records merit further investigation.

\section{b. Recent increased covariability of TCG latitude and longitude}

During recent decades, TCG latitude and longitude over the WNP show increased interannual covariability. As shown in Table 1, a significant linkage between TCG latitude and TCG longitude over the WNP basin occurs with a correlation coefficient of -0.54 . The significant association between TCG latitude and longitude over the whole period of 1979-2016 is mainly due to a significant correlation between the two parameters during recent decades. During 1998-2016, TCG latitude strongly correlates $(-0.58)$ with TCG longitude (Fig. 1). In contrast, the correlation between TCG latitude and TCG longitude $(-0.38)$ is not significant before 1998 (Fig. 1). Similar results in interannual covariability of TCG latitude and longitude are found when examining the MDR. The interannual correlation is an insignificant -0.08 during
1979-97 but is a significant -0.50 during 1998-2016. This indicates that the recent intensified interannual relationship between TCG latitude and longitude is closely associated with decadal changes in the spatial distribution of TCG over the WNP basin. Moreover, such an intensified covariability in TCG latitude and longitude over the WNP basin is also found when examining the other two best-track datasets: JMA and CMA_STI. Insignificant interannual correlations of $-0.19 / 0.19$ during 1979-97 and significant correlations of $-0.52 /-0.59$ during 1998-2016 between TCG latitude and longitude are obtained when using the CMA_STI and JMA datasets, indicated as previously. This strong consistency among the three best-track datasets confirms the intensified covariability of TCG latitude and longitude over the WNP during the recent decades. We focus on improving our understanding of the recent increased covariability of TCG latitude and longitude over the WNP basin for the remainder of this study.

\section{Possible factors for the recent increased covariability of TCG latitude and longitude}

Figure 3 displays a correlation map between SST and TCG location since 1998 and before 1998. During 19982016, the correlation pattern between TCG latitude and SST is very similar to the correlation pattern between TCG longitude and SST (Figs. 3b,d). Both patterns have a significant correlation over the tropical $\mathrm{CP}$ region and both generally show a CP ENSO-like pattern. The 
(a) 1979-1997 La Nina/MJJASON

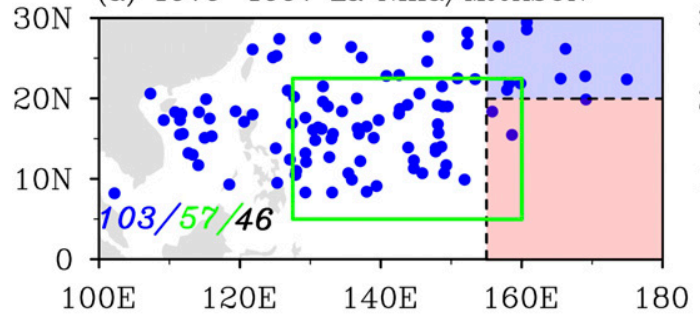

(c) 1998-2016 La Nina/MJJASON

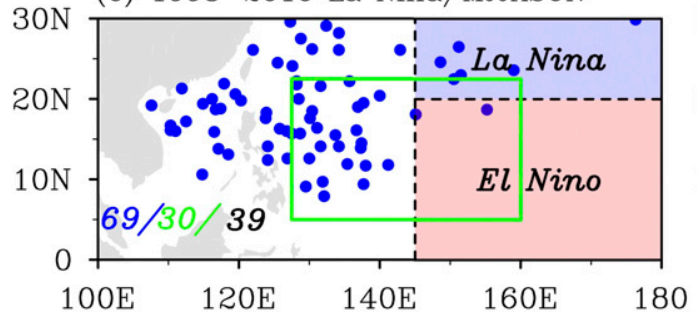

(b) 1979-1997 El Nino/MJJASON

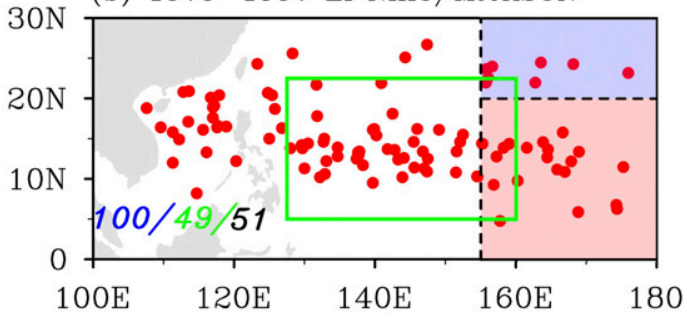

(d) 1998-2016 El Nino/MJJASON

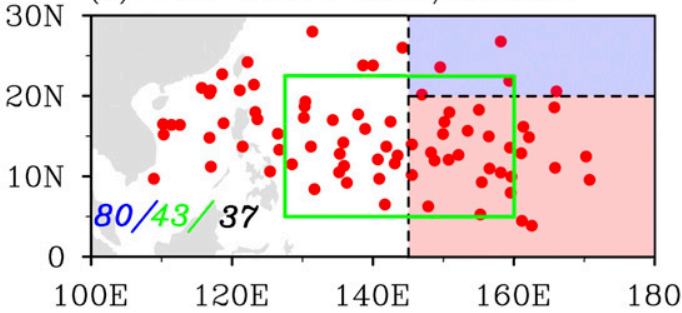

FIG. 4. May-November TCG location during the (left) four highest and (right) four lowest Southern Oscillation index (SOI) years [as defined in Lander (1994)] for (a),(b) 1979-97 and (c),(d) 1998-2016, averaged from March to January. The red- and blue-background regions are El Niño and La Niña boxes, respectively. The green-outlined box is the MDR. The TC counts in the whole WNP (blue number), the MDR (green number), and outside the MDR (black number) are also listed.

consistency in the correlation map between SST and both TCG latitude and TCG longitude corresponds well with the increased covariability of TCG latitude and TCG longitude during the recent decades. By contrast, there are differences in the correlation maps of TCG latitude and especially TCG longitude from 1979-97 to 1998-2016 (Figs. 3a,c). During the earlier period, TCG latitude correlates significantly with SST over the tropical Pacific, especially the tropical central-eastern Pacific. The pattern of the TCG latitude-SST correlation in the Pacific is similar during the recent period, although the correlation in the western Pacific is less significant. The significance of the positive correlation between tropical central-eastern Pacific SST and tropical Indian Ocean (TIO) SST and TCG longitude has increased from the earlier period to the more recent period. The physical differences in the TCG latitude and TCG longitude relationships with SST are likely the reason that there are insignificant correlation between TCG latitude and TCG longitude over the WNP basin during 1979-97, whereas the relationship is significant since that time.

These results are further demonstrated by the pattern correlation of these two correlation maps for the periods of 1979-97 and 1998-2016. The pattern correlations are -0.56 and -0.92 during 1979-97 and 1998-2016, respectively. As suggested by Wilks (2006), a pattern correlation of 0.6 represents a reasonable lower limit for significance. This significance level has been widely used in previous studies (Barnston and Mason 2011; Zhao et al. 2014; Zhao and Wang 2016, 2019). In general, this implies that a shifting ENSO state possibly played a role in controlling changes of interannual covariability of TCG latitude and longitude over the WNP basin.

As suggested by previous studies that showed a significant impact of ENSO on WNP TCG location (Lander 1994; Wang and Chan 2002), we also plotted the TCG distribution during El Niño and La Niña years for the two periods (Fig. 4). A significant difference between El Niño and La Niña years occurs during recent decades over the MDR, but it is not significant during 1979-97. The difference of 4 TCs between El Niño and La Niña years during 1979-97 is not significant at a $95 \%$ confidence level, whereas the difference of 13 TCs during 1998-2016 is significant at a 95\% confidence level. Additionally, there is no significant difference of TCs forming outside the MDR between El Niño and La Niña years between the two periods. A total of 46 and 39 TCs occurred outside the MDR during La Niña years for 1979-97 and 1998-2016, respectively, and the corresponding numbers are 51 and 37 TCs during El Niño years. The differences are 5 and 2 between El Niño and La Niña years during 1979-97 and 1998-2016, respectively, both of which are not significant at a $95 \%$ confidence level. Similarly, TCs in the South China Sea (SCS) showed no significant change between the two periods. A total of 18 and 16 TCs occurred in the SCS during La Niña years for 1979-97 and 1998-2016, respectively, and the corresponding numbers are 19 and 13 
(a) La Nina/EARLY SEASON

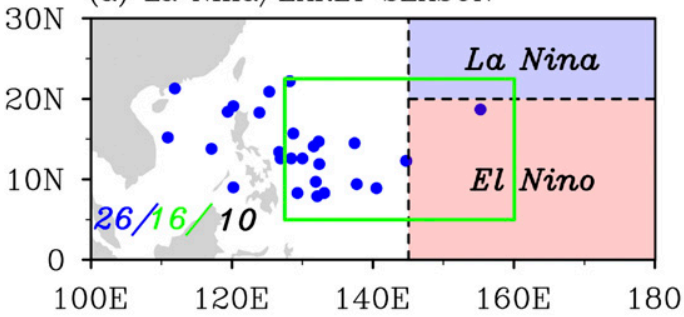

(b) La Nina/MID SEASON

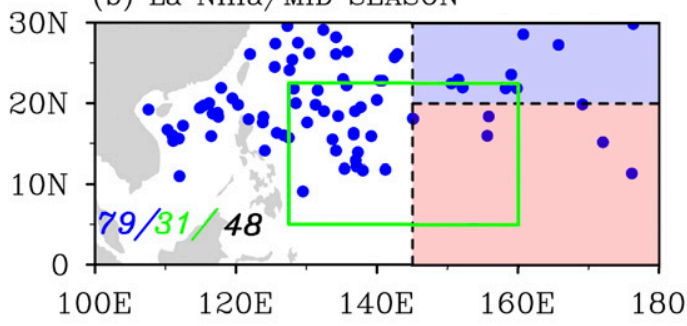

(c) La Nina/LATE SEASON

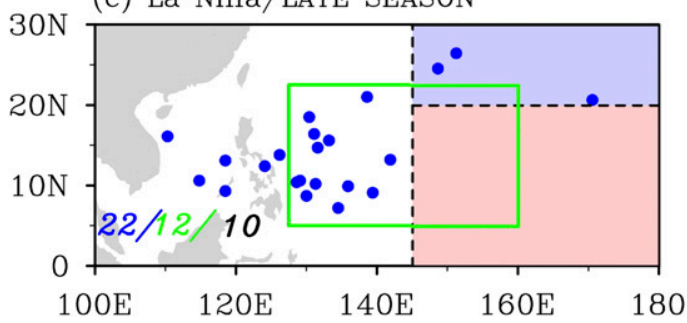

(d) El Nino/EARLY SEASON

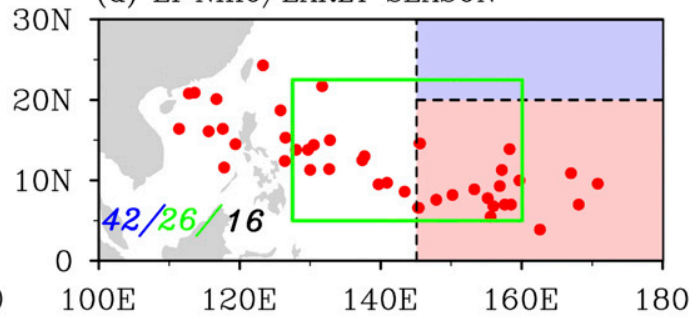

(e) El Nino/MID SEASON

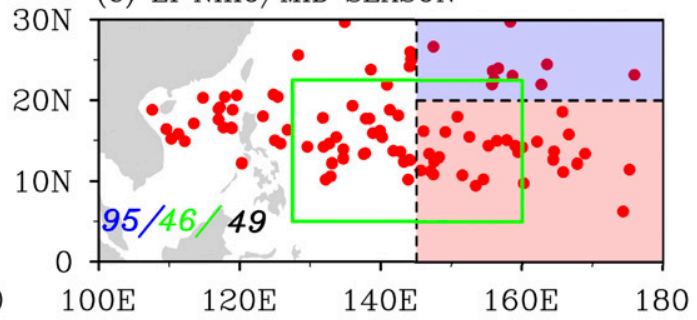

(f) El Nino/LATE SEASON

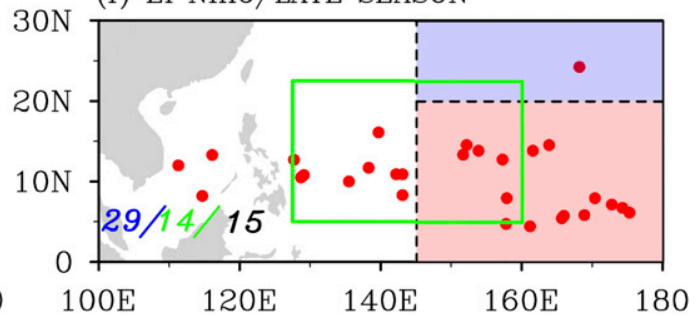

FIG. 5. TCG location in different seasons [(top) early season, (middle) midseason, and (bottom) late season (bottom)] during the (a)-(c) six highest and (d)-(f) six lowest Southern Oscillation index (SOI) years [as defined in Lander (1994)], averaged from March to January during 1979-2016. The red- and blue-background regions are El Niño and La Niña boxes, respectively. The green-outlined box is the MDR. The TC counts in the whole WNP (blue number), the MDR (green number) and outside the MDR (black number) are also listed. The early season is defined from March to mid-July, the midseason goes from mid-July to mid-October, and the late season covers from mid-October to January of the following year (Lander 1994).

TCs during El Niño years. The period differences of 1 and 3 between El Niño and La Niña years are not significant at a $95 \%$ confidence level.

Furthermore, the TCG distribution during the early season (March to mid-July), the midseason (mid-July to mid-October), and the late season (mid-October to January) during El Niño and La Niña years for the two periods, 1979-97 and 1998-2016, are also plotted following Lander (1994). As shown in Fig. 5, TC genesis during the period from 1979 to 2016 is strongly influenced by ENSO, which is clearly seen in the so-called El Niño box. This is consistent with the results of Lander (1994). We find a similar impact of ENSO on TC genesis in the El Niño box during both subperiods (Figs. 6 and 7). In addition, we find that ENSO has a significant impact on MDR TC genesis during 1998-2016 for the early season, the midseason, and the late season, but it has no significant impact on MDR TC genesis for the early season and the midseason during 1979-97 (Figs. 6 and 7).
In contrast, ENSO has a significant impact on TC genesis outside the MDR in the late season during 1979-97 (Figs. 6 and 7). Seasonal impacts of ENSO on TC genesis appear to be related to interdecadal changes. This finding warrants future research.

To further clarify the importance of the ENSO state change on the TCG location-SST relationship, the relationships between various ENSO indices and TCG location between before 1998 and after 1998 are examined. An intensified and significant correlation between both TCG latitude and longitude and the EMI or CP ENSO index has been recorded during recent decades. These correlations are significant, -0.77 and 0.61 , respectively (Table 2). In contrast, the correlations between TCG location and ENSO are lower during 197997 (Table 2). In association with prevailing EP ENSO events during 1979-97, we also computed the correlation of EP ENSO events with TCG latitude and longitude. The EP ENSO index significantly correlates with 
(a) La Nina/EARLY SEASON

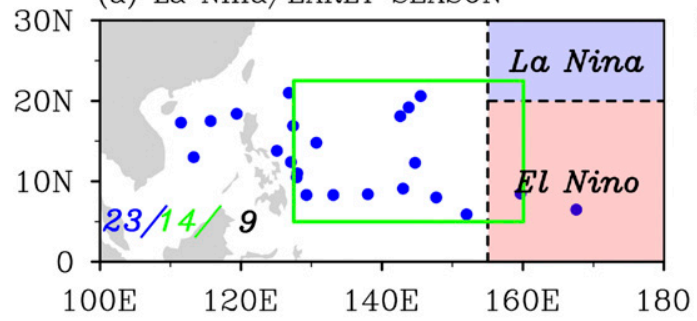

(b) La Nina/MID SEASON

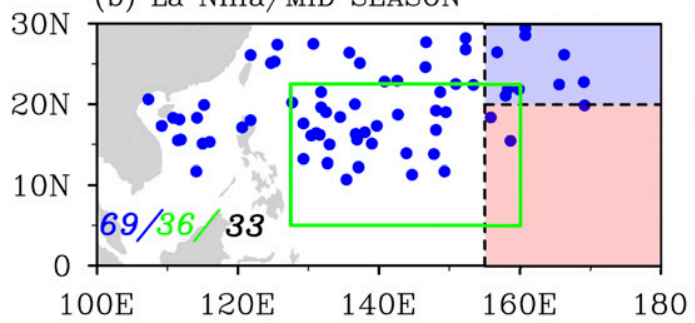

(c) La Nina/LATE SEASON

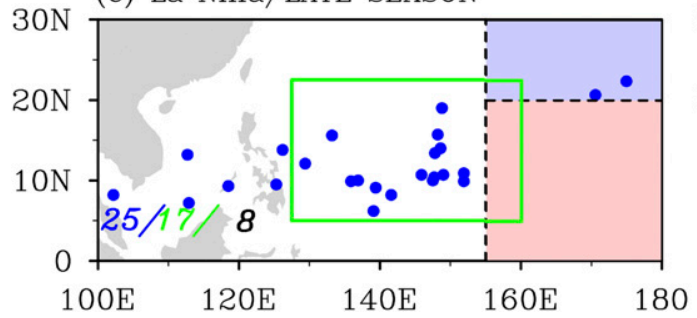

(d) El Nino/EARLY SEASON

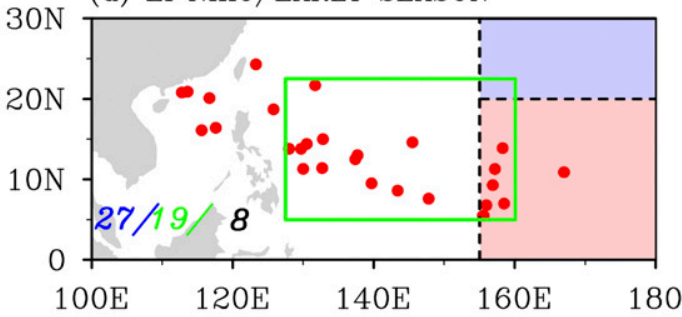

(e) El Nino/MID SEASON

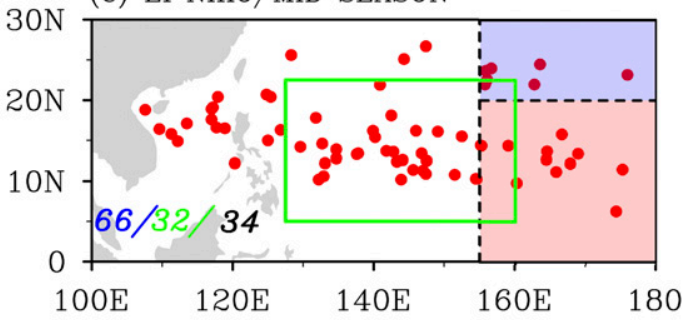

(f) El Nino/LATE SEASON

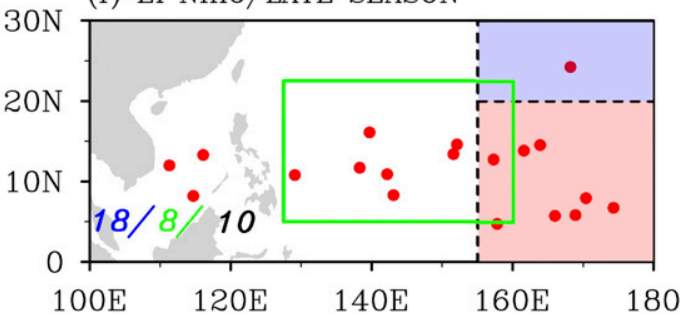

FIG. 6. As in Fig. 5, but for the four highest and four lowest SOI years during 1979-97.

TCG latitude ( -0.53$)$ but not with TCG longitude (0.29) (Table 2). In summary, CP ENSO events significantly correlate with both TCG latitude and TCG longitude, whereas EP ENSO events significantly correlate with TCG latitude but not with TCG longitude. Similar results can also be found in the interannual relationship between TCG latitude and longitude over the MDR. During the recent decades, the correlation between TCG latitude or longitude over this region and the CP ENSO index is -0.54 and 0.63 , respectively, both of which are significant. In summary, we find that the recent intensification of the covariability of TCG latitude and longitude over the WNP basin is largely due to the increasing frequency of CP ENSO events associated with the climate regime shift.

As discussed in Verdon and Franks (2006), there is evidence to link the prevalence of one type of El Niño event or the other to decadal variations of the mean Pacific state associated with the PDO. The cold phase of the PDO that has tended to predominate since the late 1990s is likely to favor La Niña or CP El Niño events. Recent studies have also demonstrated a regime shift in ENSO in recent decades with more frequent La Niña and CP El Niño events (Kao and Yu 2009; Cai et al.
2015; Xiang et al. 2013). Further analyses suggest a more consistent covariability of TC genesis latitude and longitude during the years with a negative PDO index with a correlation coefficient of -0.60 (significant at a $95 \%$ confidence level), whereas this covariability is reduced during the years with a positive PDO (correlation coefficient is -0.34) (Fig. 8).

Several studies have documented that changes in TCG location over the WNP basin largely depend on changes in the intensity of the Walker circulation and the Hadley circulation (Chu 2002; Wang and Enfield 2003; Zhou and Cui 2008; Wang et al. 2013; Sharmila and Walsh 2018; Studholme and Gulev 2018). Associated with the general shift of El Niño events from the eastern to the central Pacific in recent decades, studies have suggested that there has been a substantial strengthening of the Walker circulation and a pronounced northward expansion of the Hadley circulation (McGregor et al. 2014; Sharmila and Walsh 2018). Given that there is a close linkage between TCG location over the WNP basin with both the Walker and the Hadley circulations, the changes in the interannual relationship between TCG location and the intensity of both the Hadley and Walker circulations are investigated. There is a 
(a) La Nina/EARLY SEASON

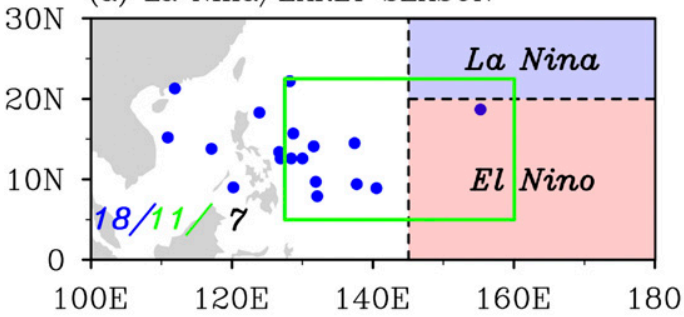

(b) La Nina/MID SEASON

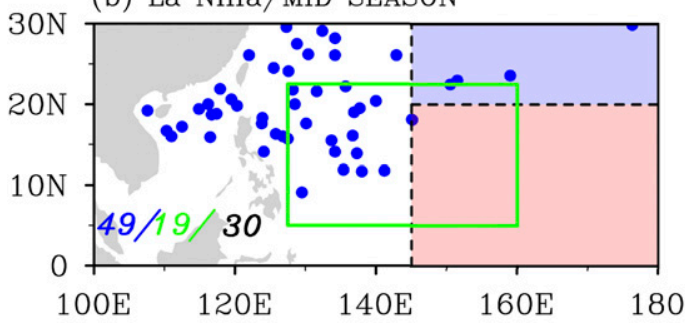

(c) La Nina/LATE SEASON

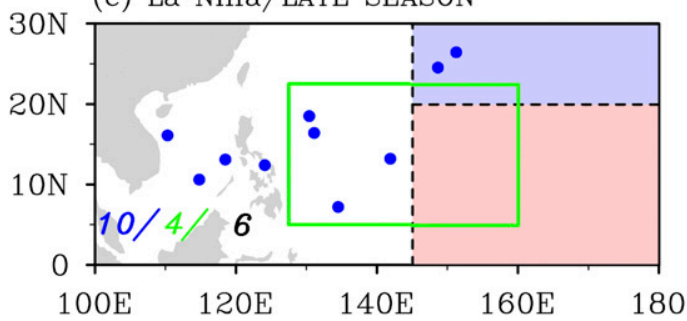

(d) El Nino/EARLY SEASON

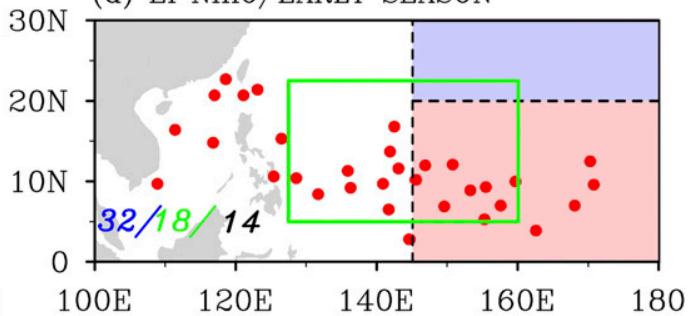

(e) El Nino/MID SEASON

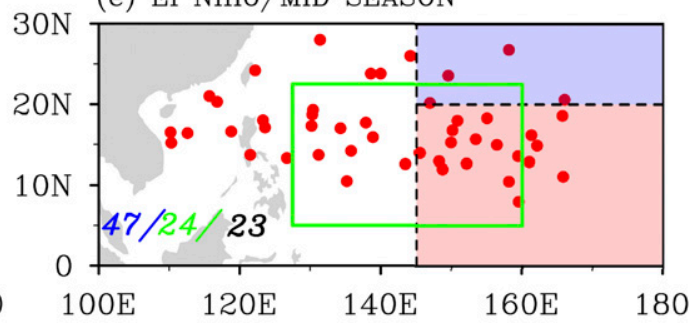

(f) El Nino/LATE SEASON

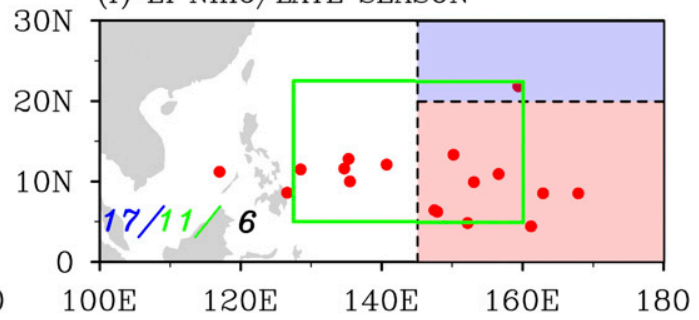

FIG. 7. As in Fig. 6, but for 1998-2016.

significant relationship between TCG latitude and the intensity of the Hadley circulation and between longitude and the intensity of the Walker circulation for both periods (Fig. 9). There are significant correlations between TCG latitude and the intensity of the Hadley circulation during both 1979-97 (correlation is -0.51) and 1998-2016 (correlation is -0.67), respectively. Similarly, correlations between TCG longitude and the intensity of the Walker circulation are also significant during both 1979-97 (-0.62) and 1998-2016 (-0.75). We next investigate how shifting ENSO conditions impact the Hadley and Walker circulations (Fig. 10). As expected, the CP ENSO index has a significant correlation with the intensity of the Hadley circulation (0.73)

TABLE 2. Correlations between both TCG latitude and TCG longitude from JTWC and various ENSO indices during 1998-2016 and 1979-97. An asterisk indicates that the correlation is significant at a $95 \%$ confidence level.

\begin{tabular}{lccccc}
\hline \hline & \multicolumn{2}{c}{ TCG lat } & & \multicolumn{2}{c}{ TCG lon } \\
\cline { 2 - 3 } \cline { 5 - 6 } & $1979-97$ & $1998-2016$ & & $1979-97$ & $1998-2016$ \\
\hline EMI & -0.15 & $-0.77^{*}$ & & 0.15 & $0.61^{*}$ \\
EP ENSO index & $-0.53^{*}$ & 0.24 & & 0.29 & -0.08 \\
CP ENSO index & -0.15 & $-0.78^{*}$ & & 0.24 & $0.63^{*}$ \\
\hline
\end{tabular}

and the Walker circulation (0.74) during the recent period, while these correlations were insignificant during 1979-97. During 1979-97, the CP ENSO index correlates insignificantly $(0.22)$ with the intensity of the Hadley circulation and correlates insignificantly $(0.38)$ with the intensity of the Walker circulation. In summary, these analyses suggest that the recent increased

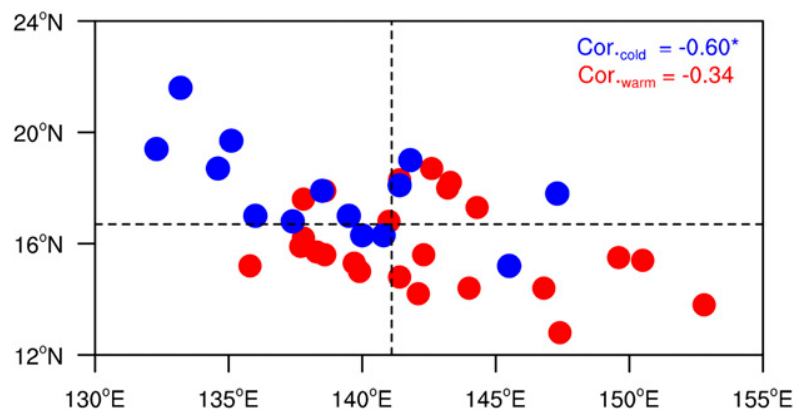

FIG. 8. Annual May-November averaged TCG latitude and TCG longitude during years with a positive PDO index (red) or a negative PDO index (blue) during 1979-2016. The corresponding correlation coefficients are also listed. The intersection of the horizontal and the vertical dashed lines represents the averaged TCG longitude and TCG latitude during 1979-2016. The value with an asterisk is significant at a $95 \%$ confidence level. 

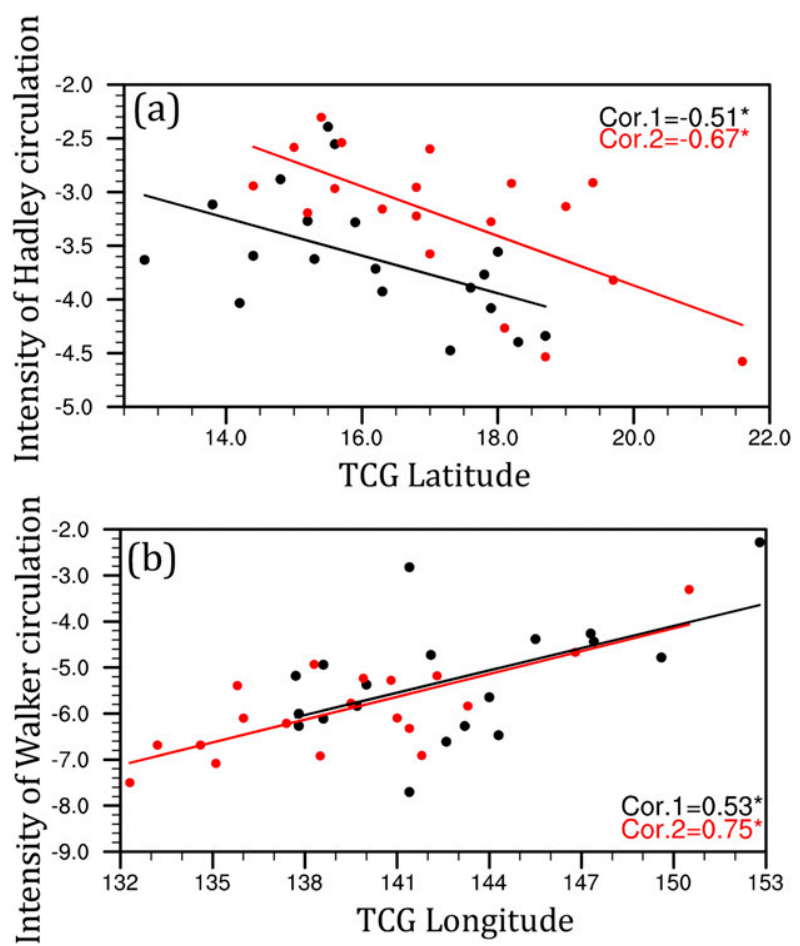

FIG. 9. (a) Scatterplot between the intensity of the Hadley circulation $\left(\mathrm{m} \mathrm{s}^{-1}\right)$ and TCG latitude from JTWC during 1979-97 (black) and during 1998-2016 (red). The black and red lines denote the linear fit by least squares means during 1979-97 and 1998-2016, respectively. (b) As in (a), but for a scatterplot between the intensity of the Walker circulation $\left(\mathrm{m} \mathrm{s}^{-1}\right)$ and TCG longitude from JTWC. Correlation coefficients are also displayed.

covariability of TCG latitude and longitude over the WNP basin is possibly due to the increasing association of CP ENSO with both the intensity of the Walker circulation and the Hadley circulation.

\section{Summary and discussion}

The impacts of the Pacific climate regime shift and a shifting ENSO on WNP TCs have been highlighted in several studies that have investigated its influence on decadal time scales on TC frequency, intensity, and track. These changes are attributed to differences in both large-scale factors as well as related teleconnections (Liu and Chan 2013; Lin and Chan 2015; Hu et al. 2018; Wu et al. 2018; Zhao et al. 2018; Zhao and Wang 2016, 2019). However, the interannual relationship between TCG latitude and TCG longitude over the WNP basin associated with the climate regime shift has been less studied.

In this study, the recently increased interannual covariability of WNP TCG latitude and longitude is demonstrated to be tied to the climate regime shift that occurred in 1998. During recent decades, there has been an increasing occurrence of CP ENSO events and a transition from a warm PDO phase to a cool PDO phase (Weisberg and Wang 1997; Wang et al. 2013; Hsu et al. 2014; Wang et al. 2015; Hong et al. 2016; Zhao and Wang 2016, 2019; Zhao et al. 2018; Hu et al. 2018). Our results suggest that CP ENSO events show a consistent and strong linkage with TCG location over the WNP basin during recent decades and thus have resulted in an increased covariability of TCG latitude and longitude over the WNP basin. In contrast, EP ENSO events played an important role in controlling the zonal shift of TCG location during the period from 1979-97 but had little impact on the meridional displacement of TCG.

Our analyses further suggest that the recent increased covariability of TCG location is closely associated with changes in the spatial distribution of TCG location that

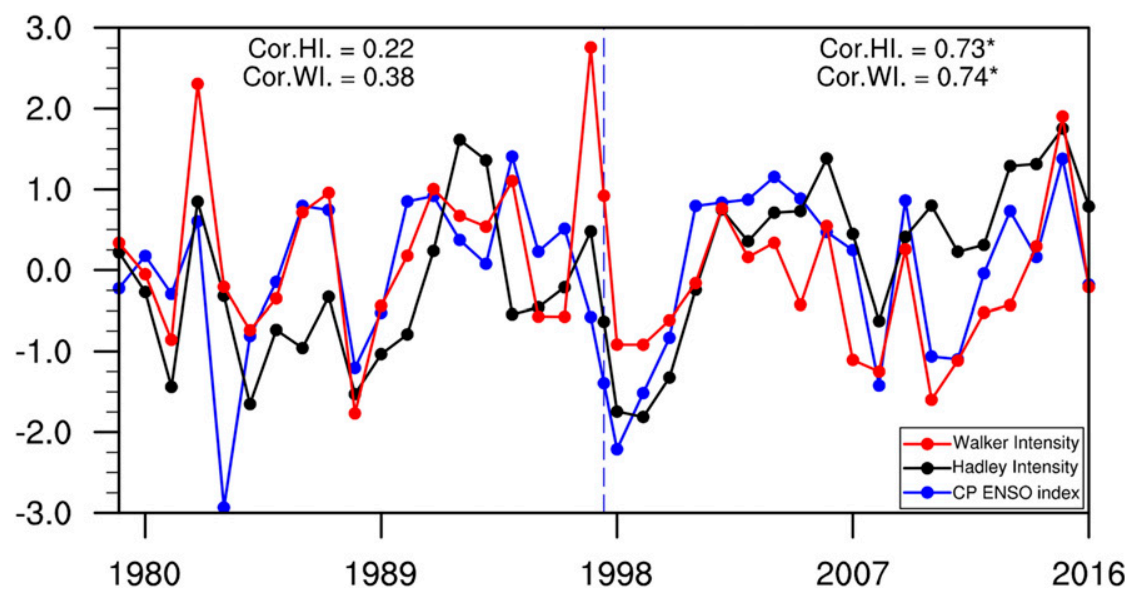

FIG. 10. Normalized time series of the Walker circulation intensity (WI), the Hadley circulation intensity (HI), and the CP ENSO index. Correlations between the HI or WI and CP ENSO index during 1979-97 and 1998-2016 are also plotted. An asterisk indicates that the correlation is significant at a $95 \%$ confidence level. 
occurred in the late 1990s. Several studies have discussed the likely physical mechanisms underlying the changes in the spatial distribution of TCG (Liu and Chan 2013; Hsu et al. 2014; Lin et al. 2015; Wu et al. 2015; Zhao and Wang 2016, 2019; Hu et al. 2018). This study focuses on changes in the interannual relationship between both the Walker and Hadley circulations and ENSO state changes to understand the recently increased covariability of TCG latitude and longitude over the WNP basin.

During the recent decades, there is an intensified interannual relationship between the CP ENSO index and the intensity of both the Walker circulation and the Hadley circulation. Studies have suggested that the recent increase in the occurrence of CP ENSO events is related to a strengthening of the mean Walker circulation and the Hadley circulation (Yeh et al. 2009; Yu et al. 2012; McGregor et al. 2014). A strengthening of the tropical Pacific trade winds since the late 1990s has caused a strengthening of Indo-Pacific Ocean currents, an increased uptake of heat in the equatorial Pacific thermocline, and a corresponding intensification of the atmospheric Walker circulation and Hadley circulations associated with SST cooling in the eastern Pacific. These changes may be a result of anthropogenic climate change (Vecchi and Soden 2007). Additionally, some studies have suggested that the recent strengthening of the Walker circulation and eastern Pacific cooling is amplified by Atlantic Ocean warming (McGregor et al. 2014). Also, the recent poleward migration of TC lifetime maximum intensity could possibly be associated with the expansion of the tropical belt caused by anthropogenic warming (Kossin et al. 2014, 2016; Lucas et al. 2014). The underlying physical mechanism on the changing linkage of ENSO events and the Hadley and Walker circulations merits further investigation.

Our statistical results suggest a robust and stable relationship between TCG latitude and the intensity of the Hadley circulation and between longitude and the intensity of the Walker circulation. Figure 9 presents possible evidence that shifting ENSO conditions modulate changes in the interannual relationship with both the Walker and Hadley circulations and thus the covariability of TCG latitude and longitude over the WNP basin. We note that we have emphasized the importance of an ENSO state change. As shown in Fig. 3, changes in TIO SST may also be partly responsible for the increased relationship. The associated physical processes of how TIO SST relates to the increased covariability of TCG location over the WNP basin in the recent decades remains unclear and needs further investigation.

We should caution that the results of this study are based on correlation analyses, which do not necessarily imply causality. Therefore, more observational and numerical experiments are needed to further confirm and reveal the underlying physical processes driving the observed significant increased covariability of TCG latitude and longitude over the WNP basin during recent decades. Moreover, given that more CP ENSO events are projected under the background of anthropogenic climate change, this implies that there could be a consistent northwestward shift in TCG location over the WNP basin in the future. Such a shift could impose an increased threat to Japan, China, the Korean Peninsula, the Philippines, and Taiwan, similar to what we see during La Niña periods.

Acknowledgments. This research was jointly supported by the National Natural Science Foundation of China (Grants 41675072, 41922033, and 41675051), the QingLan Project of Jiangsu Province (R2017Q01), the project of the "Six Talent Peaks Project in Jiangsu Province" (2019-JY-100), and the Priority Academic Program Development of Jiangsu Higher Education Institutions (PAPD). Author Klotzbach acknowledges a grant from the G. Unger Vetlesen Foundation. TC data are obtained from the JTWC best-track dataset. Atmospheric fields were obtained from the National Centers for Environmental Prediction-U.S. Department of Energy. The monthly mean SST is from NOAA. The SST dataset was from ERSSTv4 (Extended Reconstruction SST, version 4), which was provided by NOAA.

\section{REFERENCES}

Ashok, K., S. K. Behera, S. A. Rao, H. Weng, and T. Yamagata, 2007: El Niño Modoki and its possible teleconnection. J. Geophys. Res. Oceans, 112, C11007, https://doi.org/10.1029/ 2006JC003798.

Barnston, A. G., and S. J. Mason, 2011: Evaluation of IRI's seasonal climate forecasts for the extreme $15 \%$ tails. Wea. Forecasting, 26, 545-554, https://doi.org/10.1175/WAF-D-10-05009.1.

Cai, W., and Coauthors, 2015: ENSO and greenhouse warming. Nat. Climate Change, 5, 849-859, https://doi.org/10.1038/ nclimate2743.

Camargo, S. J., and A. H. Sobel, 2005: Western North Pacific tropical cyclone intensity and ENSO. J. Climate, 18, 29963006, https://doi.org/10.1175/JCLI3457.1.

Chan, J. C. L., 2008: Decadal variations of intense typhoon occurrence in the western North Pacific. Proc. Roy. Soc., 464A, 249-272, https://doi.org/10.1098/RSPA.2007.0183.

Chen, G., and C.-Y. Tam, 2010: Different impacts of two kinds of Pacific Ocean warming on tropical cyclone frequency over the western North Pacific. Geophys. Res. Lett., 37, L01803, https:// doi.org/10.1029/2009GL041708.

Chu, J. H., C. R. Sampson, A. S. Levin, and E. Fukada, 2002: The Joint Typhoon Warning Center tropical cyclone best tracks 1945-2000. Joint Typhoon Warning Center, https:// www.usno.navy.mil/NOOC/nmfc-ph/RSS/jtwc/best_tracks/ TC_bt_report.html. 
Chu, P.-S., 2002: Large-scale circulation features associated with decadal variations of tropical cyclone activity over the central North Pacific. J. Climate, 15, 2678-2689, https://doi.org/10.1175/ 1520-0442(2002)015<2678:LSCFAW > 2.0.CO;2.

Gao, S., Z. Chen, and W. Zhang, 2018: Impacts of tropical North Atlantic SST on western North Pacific landfalling tropical cyclones. J. Climate, 31, 853-862, https://doi.org/10.1175/JCLID-17-0325.1.

Hong, C.-C., Y.-H. Li, T. Li, and M.-Y. Lee, 2011: Impacts of central Pacific and eastern Pacific El Niños on tropical cyclone tracks over the western North Pacific. Geophys. Res. Lett., 38, L16712, https://doi.org/10.1029/2011GL048821.

— , Y.-K. Wu, and T. Li, 2016: Influence of climate regime shift on the interdecadal change in tropical cyclone activity over the Pacific Basin during the middle to late 1990s. Climate Dyn., 47, 2587-2600, https://doi.org/10.1007/s00382-016-2986-x.

Hoyos, C. D., and P. J. Webster, 2012: Evolution and modulation of tropical heating from the last glacial maximum through the twenty-first century. Climate Dyn., 38, 1501-1519, https:// doi.org/10.1007/s00382-011-1181-3.

Hsu, P.-C., P.-S. Chu, H. Murakami, and X. Zhao, 2014: An abrupt decrease in the late-season typhoon activity over the western North Pacific. J. Climate, 27, 4296-4312, https://doi.org/ 10.1175/JCLI-D-13-00417.1.

Hu, C., C. Zhang, S. Yang, D. Chen, and S. He, 2018: Perspective on the northwestward shift of autumn tropical cyclogenesis locations over the western North Pacific from shifting ENSO. Climate Dyn., 51, 2455-2465, https://doi.org/10.1007/s00382017-4022-1.

Hu, Z.-Z., A. Kumar, H. L. Ren, H. Wang, M. L'Heureux, and F. F. Jin, 2013: Weakened interannual variability in the tropical Pacific Ocean since 2000. J. Climate, 26, 2601-2613, https:// doi.org/10.1175/JCLI-D-12-00265.1.

,-- , B. Huang, J. Zhu, and H. L. Ren, 2017: Interdecadal variations of ENSO around 1999/2000. J. Meteor. Res., 31, 7381, https://doi.org/10.1007/s13351-017-6074-x.

Huang, B., and Coauthors, 2015: Extended reconstructed sea surface temperature version 4 (ERSST.v4). Part I: Upgrades and intercomparisons. J. Climate, 28, 911-930, https://doi.org/ 10.1175/JCLI-D-14-00006.1.

Huo, L., P. Guo, S. N. Hameed, and D. Jin, 2015: The role of tropical Atlantic SST anomalies in modulating western North Pacific tropical cyclone genesis. Geophys. Res. Lett., 42, 2378 2384, https://doi.org/10.1002/2015GL063184.

Kanamitsu, M., W. Ebisuzaki, J. Woollen, S. K. Yang, J. J. Hnilo, M. Fiorino, and G. L. Potter, 2002: NCEP-DOE AMIP-II reanalysis (R-2). Bull. Amer. Meteor. Soc., 83, 1631-1643, https://doi.org/10.1175/BAMS-83-11-1631.

Kao, H.-Y., and J.-Y. Yu, 2009: Contrasting eastern-Pacific and central-Pacific types of ENSO. J. Climate, 22, 615-632, https:// doi.org/10.1175/2008JCLI2309.1.

Kim, H.-M., P. J. Webster, and J. A. Curry, 2009: Impact of shifting patterns of Pacific Ocean warming on North Atlantic tropical cyclones. Science, 325, 77-80, https://doi.org/10.1126/science. 1174062

Kim, J.-H., C.-H. Ho, and P.-S. Chu, 2010: Dipolar redistribution of summertime tropical cyclone genesis between the Philippine Sea and the northern South China Sea and its possible mechanisms. J. Geophys. Res., 115, D06104, https://doi.org/ 10.1029/2009JD012196.

Knutson, T. R., and Coauthors, 2010: Tropical cyclones and climate change. Nat. Geosci., 3, 157-163, https://doi.org/10.1038/ ngeo779.
Kossin, J. P., K. A. Emanuel, and G. A. Vecchi, 2014: The poleward migration of the location of tropical cyclone maximum intensity. Nature, 509, 349-352, https://doi.org/10.1038/nature13278.

$\_,-$_, and S. J. Camargo, 2016: Past and projected changes in western North Pacific tropical cyclone exposure. J. Climate, 29, 5725-5739, https://doi.org/10.1175/JCLI-D-16-0076.1.

Kug, J.-S., K. P. Sooraj, D. Kim, I.-S. Kang, F.-F. Jin, Y. N. Takayabu, and M. Kimoto, 2009: Simulation of statedependent high-frequency atmospheric variability associated with ENSO. Climate Dyn., 32, 635-648, https://doi.org/ 10.1007/s00382-008-0434-2.

Kunitsugu, M., 2012: Tropical cyclone information provided by the RSMC Tokyo-Typhoon Center. Trop. Cyclone Res. Rev., 1, 51-59, https://doi.org/10.6057/2012TCRR01.06.

Lander, M. A., 1994: An exploratory analysis of the relationship between tropical storm formation in the western North Pacific and ENSO. Mon. Wea. Rev., 122, 636-651, https://doi.org/ 10.1175/1520-0493(1994)122<0636:AEAOTR >2.0.CO;2.

Lee, T., and M. J. McPhaden, 2010: Increasing intensity of El Niño in the central-equatorial Pacific. Geophys. Res. Lett., 37, L14603, https://doi.org/10.1029/2010GL044007.

Lin, I.-I., and J. C. L. Chan, 2015: Recent decrease in typhoon destructive potential and global warming implications. Nat. Commun., 6, 7182, https://doi.org/10.1038/NCOMMS8182.

- I.-F. Pun, and C.-C. Lien, 2014: "Category-6" supertyphoon Haiyan in global warming hiatus: Contribution from subsurface ocean warming. Geophys. Res. Lett., 41, 8547-8553, https://doi.org/10.1002/2014GL061281.

Liu, K. S., and J. C. L. Chan, 2013: Inactive period of western North Pacific tropical cyclone activity in 1998-2011. J. Climate, 26, 2614-2630, https://doi.org/10.1175/JCLI-D-12-00053.1.

Lucas, C., B. Timbal, and H. Nguyen, 2014: The expanding tropics: A critical assessment of the observational and modeling studies. Wiley Interdiscip. Rev. Climate Change, 5, 89-112, https://doi.org/10.1002/wcc.251.

McGregor, S., A. Timmermann, M. F. Stuecker, M. H. England, M. Merrifield, F. F. Jin, and Y. Chikamoto, 2014: Recent Walker circulation strengthening and Pacific cooling amplified by Atlantic warming. Nat. Climate Change, 4, 888-892, https:// doi.org/10.1038/nclimate2330.

McPhaden, M. J., T. Lee, and D. McClurg, 2011: El Niño and its relationship to changing background conditions in the tropical Pacific Ocean. Geophys. Res. Lett., 38, L15709, https://doi.org/ 10.1029/2011GL048275.

Mendelsohn, R., K. Emanuel, S. Chonabayashi, and L. Bakkensen, 2012: The impact of climate change on global tropical cyclone damage. Nat. Climate Change, 2, 205-209, https://doi.org/ 10.1038/nclimate1357.

Oort, A. H., and J. J. Yienger, 1996: Observed interannual variability in the Hadley circulation and its connection to ENSO. J. Climate, 9, 2751-2767, https://doi.org/10.1175/1520-0442(1996)009<2751: OIVITH $>2.0 . \mathrm{CO} ; 2$.

Peduzzi, P., B. Chatenoux, H. Dao, A. De Bono, C. Herold, J. Kossin, F. Mouton, and O. Nordbeck, 2012: Global trends in tropical cyclone risk. Nat. Climate Change, 2, 289-294, https:// doi.org/10.1038/nclimate1410.

Sharmila, S., and K. J. E. Walsh, 2018: Recent poleward shift of tropical cyclone formation linked to Hadley circulation expansion. Nat. Climate Change, 8, 730-736, https://doi.org/ 10.1038/s41558-018-0227-5.

Studholme, J., and S. Gulev, 2018: Concurrent changes to Hadley circulation and the meridional distribution of tropical cyclones. J. Climate, 31, 4367-4389, https://doi.org/10.1175/JCLI-D-17-0852.1. 
Vecchi, G. A., and B. J. Soden, 2007: Global warming and the weakening of the tropical circulation. J. Climate, 20, 43164340, https://doi.org/10.1175/JCLI4258.1.

$\longrightarrow,-$, A. T. Wittenberg, I. M. Held, A. Leetmaa, and M. J. Harrison, 2006: Weakening of tropical Pacific atmospheric circulation due to anthropogenic forcing. Nature, 441, 73-76, https://doi.org/10.1038/nature04744.

Verdon, D. C., and S. W. Franks, 2006: Long-term behaviour of ENSO: Interactions with the PDO over the past 400 years inferred from paleoclimate records. Geophys. Res. Lett., 33, L06712, https://doi.org/10.1029/2005GL025052.

Walsh, K. J. E., and Coauthors, 2015: Hurricanes and climate: The U.S. CLIVAR Working Group on Hurricanes. Bull. Amer. Meteor. Soc., 96, 997-1017, https://doi.org/10.1175/BAMS-D13-00242.1.

Wang, B., and J. C. L. Chan, 2002: How strong ENSO events affect tropical storm activity over the western North Pacific. J. Climate, 15, 1643-1658, https://doi.org/10.1175/1520-0442(2002)015<1643: HSEEAT > 2.0.CO;2.

— J. J. Liu, H.-J. Kim, P. J. Webster, S.-Y. Yim, and B. Xiang, 2013: Northern Hemisphere summer monsoon intensified by mega-El Niño/Southern Oscillation and Atlantic multidecadal oscillation. Proc. Natl. Acad. Sci. USA, 110, 5347-5352, https:// doi.org/10.1073/pnas.1219405110.

Wang, C., and D. B. Enfield, 2003: A further study of the tropical Western Hemisphere warm pool. J. Climate, 16, 1476-1493, https://doi.org/10.1175/1520-0442-16.10.1476.

_- B. Wang, and L. Wu, 2019: Abrupt breakdown of the predictability of early season typhoon frequency at the beginning of the twenty-first century. Climate Dyn., 52, 3809-3822, https://doi.org/10.1007/s00382-018-4350-9.

Weisberg, R. H., and C. Wang, 1997: A western Pacific oscillator paradigm for the El Niño-Southern Oscillation. Geophys. Res. Lett., 24, 779-782, https://doi.org/10.1029/97GL00689.

Wilks, D. S., 2006: On "field significance" and the false discovery rate. J. Appl. Meteor. Climatol., 45, 1181-1189, https://doi.org/ 10.1175/JAM2404.1.

Wu, L., C. Wang, and B. Wang, 2015: Westward shift of western North Pacific tropical cyclogenesis. Geophys. Res. Lett., $\mathbf{4 2}$, 1537-1542, https://doi.org/10.1002/2015GL063450.

_- R. Wang, and X. Feng, 2018: Dominant role of the ocean mixed layer depth in the increased proportion of intense typhoons during 1980-2015. Earth's Future, 6, 1518-1527, https://doi.org/10.1029/2018EF000973.

Xiang, B., B. Wang, and T. Li, 2013: A new paradigm for the predominance of standing central Pacific warming after the late 1990s. Climate Dyn., 41, 327-340, https://doi.org/10.1007/ s00382-012-1427-8.

Yamaguchi, M., F. Vitart, S. T. Lang, L. Magnusson, R. L. Elsberry, G. Elliott, M. Kyouda, and T. Nakazawa, 2015: Global distribution of the skill of tropical cyclone activity on short- to medium-range time scales. Wea. Forecasting, 30, 1695-1709, https://doi.org/10.1175/WAF-D-14-00136.1.

Yeh, S.-W., J.-S. Kug, B. Dewitte, M.-H. Kwon, B. P. Kirtman, and F.-F. Jin, 2009: Erratum: El Niño in a changing climate. $\mathrm{Na}$ ture, 462, 674, https://doi.org/10.1038/nature08546.

Ying, M., W. Zhang, H. Yu, X. Lu, J. Feng, Y. X. Fan, Y. Zhu, and D. Chen, 2014: An overview of the China meteorological administration tropical cyclone database. J. Atmos. Oceanic Technol., 31, 287-301, https://doi.org/10.1175/JTECH-D-12-00119.1.

Yu, J.-Y., and H.-Y. Kao, 2007: Decadal changes of ENSO persistence barrier in SST and ocean heat content indices: 19582001. J. Geophys. Res., 112, D13106, https://doi.org/10.1029/ 2006JD007654.

, and S. T. Kim, 2010: Identification of central-Pacific and eastern-Pacific types of ENSO in CMIP3 models. Geophys. Res. Lett., 37, L15705, https://doi.org/10.1029/2010GL044082. , H.-Y. Kao, T. Lee, and S. T. Kim, 2011: Subsurface ocean temperature indices for central-Pacific and eastern-Pacific types of El Niño and La Niña events. Theor. Appl. Climatol., 103, 337-344, https://doi.org/10.1007/s00704-010-0307-6.

, M. M. Lu, and S. T. Kim, 2012: A change in the relationship between tropical central Pacific SST variability and the extratropical atmosphere around 1990. Environ. Res. Lett., 7, 034025, https://doi.org/10.1088/1748-9326/7/3/034025.

— , P.-K. Kao, H. Paek, H.-H. Hsu, C.-W. Hung, M.-M. Lu, and S.-I. An, 2015: Linking emergence of the central Pacific El Niño to the Atlantic multidecadal oscillation. J. Climate, 28, 651-662, https://doi.org/10.1175/JCLI-D-14-00347.1.

Zhang, Q., L. Wu, and Q. Liu, 2009: Tropical cyclone damages in China 1983-2006. Bull. Amer. Meteor. Soc., 90, 489-495, https://doi.org/10.1175/2008BAMS2631.1.

Zhao, H., and C. Wang, 2016: Interdecadal modulation on the relationship between ENSO and typhoon activity during the late season in the western North Pacific. Climate Dyn., 47, 315-328, https://doi.org/10.1007/s00382-015-2837-1.

- and - 2019: On the relationship between ENSO and tropical cyclones in the western North Pacific during the boreal summer. Climate Dyn., 52, 275-288, https://doi.org/ 10.1007/S00382-018-4136-0.

—, P. S. Chu, P. C. Hsu, and H. Muarkami, 2014: Exploratory analysis of extremely low tropical cyclone activity during the late season of 2010 and 1998 over the western North Pacific and the South China Sea. J. Adv. Model. Earth Syst., 6, 11411153, https://doi.org/10.1002/2014MS000381.

— X. Duan, G. B. Raga, and P. J. Klotzbach, 2018: Changes in characteristics of rapidly intensifying western North Pacific tropical cyclones related to climate regime shifts. J. Climate, 31, 8163-8179, https://doi.org/10.1175/JCLI-D-18-0029.1.

Zhou, B., and X. Cui, 2008: Hadley circulation signal in the tropical cyclone frequency over the western North Pacific. J. Geophys. Res., 113, D16107, https://doi.org/10.1029/2007JD009156. 